\title{
Diabetes-associated mitochondrial DNA mutation A3243G impairs cellular metabolic pathways necessary for beta cell function
}

\author{
P. B. M. de Andrade • B. Rubi • F. Frigerio • \\ J. M. W. van den Ouweland • J. A. Maassen • \\ P. Maechler
}

Received: 24 December 2005 / Accepted: 6 April 2006 /Published online: 31 May 2006

(C) Springer-Verlag 2006

\begin{abstract}
Aims/hypothesis Mitochondrial DNA (mtDNA) mutations cause several diseases, including mitochondrial inherited diabetes and deafness (MIDD), typically associated with the mtDNA A3243G point mutation on tRNALeu gene. The common hypothesis to explain the link between the genotype and the phenotype is that the mutation might impair mitochondrial metabolism expressly required for beta cell functions. However, this assumption has not yet been tested. Methods We used clonal osteosarcoma cytosolic hybrid cells (namely cybrids) harbouring mitochondria derived from MIDD patients and containing either exclusively wild-type or mutated (A3243G) mtDNA. According to the importance of mitochondrial metabolism in beta cells, we studied the impact of the mutation on key parameters by comparing stimulation of these cybrids by the main insulin secretagogue glucose and the mitochondrial substrate pyruvate.

Results Compared with control mtDNA from the same patient, the A3243G mutation markedly modified metabolic pathways leading to a high glycolytic rate (2.8-fold increase), increased lactate production (2.5-fold), and reduced glucose oxidation $(-83 \%)$. We also observed impaired NADH responses $(-56 \%)$, negligible mitochondrial membrane potential, and reduced, only transient ATP generation. Moreover,
\end{abstract}

P. B. Andrade $\cdot$ B. Rubi $\cdot$ F. Frigerio $\cdot$ P. Maechler $(\bowtie)$

Department of Cell Physiology and Metabolism,

University Medical Center,

1 rue Michel-Servet,

CH-1211 Geneva 4, Switzerland

e-mail: pierre.maechler@medecine.unige.ch

J. M. Ouweland · J. A. Maassen

Department of Molecular Cell Biology,

Leiden University Medical Center,

Leiden, The Netherlands cybrid cells carrying patient-derived mutant mtDNA exhibited deranged cell calcium handling with increased cytosolic loads (1.4-fold higher), and elevated reactive oxygen species (2.6fold increase) under glucose deprivation.

Conclusions/interpretation The present study demonstrates that the mtDNA A3243G mutation impairs crucial metabolic events required for proper cell functions, such as coupling of glucose recognition to insulin secretion.

Keywords A3243G tRNALeu gene - ATP C Calcium ·

Diabetes · MIDD · Mitochondrial DNA ·

Mitochondrial metabolism $\cdot$ ROS

\author{
Abbreviations \\ ANT adenine nucleotide translocator \\ $\Delta \Psi_{\mathrm{m}} \quad$ mitochondrial membrane potential \\ FCCP carbonyl cyanide p-trifluoromethoxyphenyl- \\ hydrazone \\ KRBH KRB bicarbonate HEPES buffer \\ M12 patient-derived mutated mtDNA \\ MIDD mitochondrial inherited diabetes and deafness \\ (MIDD) \\ MnSOD manganese superoxide dismutase (also SOD2) \\ mtDNA mitochondrial DNA \\ rho $^{\circ} \quad$ depleted of mtDNA \\ ROS reactive oxygen species \\ SOD1 copper zinc superoxide dismutase \\ W20 patient-derived wild type mtDNA
}

\section{Introduction}

Mitochondria carry their own genome in the form of circular mitochondrial DNA (mtDNA) with only 37 genes 
(16,569 bp) encoding 13 polypeptides, 22 tRNAs and 2 ribosomal RNAs [1]. Mitochondrial protein biogenesis is determined by nuclear and mitochondrial genomes, and the few polypeptides encoded by the mtDNA are all subunits of complexes involved in oxidative phosphorylation on the electron transport chain [2]. Mutations in the mtDNA cause rare but debilitating human diseases [1], including mitochondrial inherited diabetes and deafness (MIDD). MIDD is often associated with the mtDNA A3243G point mutation on the tRNALeu gene [1,3-5], usually in heteroplasmic form, i.e. a mixture of wild-type and mutant mtDNA in patient cells. The mtDNA mutation at position 3243 is associated with complex-1 deficiency [6] and impaired respiratory chain activity [7]. Typically, mitochondrial diabetes is clinically manifested during adulthood before the age of 70 and can be differentiated from monogenic MODY due to maternal transmission, often in combination with bilateral hearing impairment [8]. The pathogenicity of this mutation is hardly detectable in the endocrine pancreas [9, 10]. Moreover, pancreatic islets of such patients may carry a low heteroplasmy percentage of the A3243G mutation, compared to other tissues [9].

Mitochondria play a key role in metabolism-secretion coupling in pancreatic beta cells, primarily through production of ATP. Elevation of the ATP:ADP ratio leads to closure of the $\mathrm{K}_{\mathrm{ATP}}$-channels with subsequent rise in cytosolic $\mathrm{Ca}^{2+}$ levels, ultimately triggering insulin secretion [11]. Moreover, mitochondrial metabolism generates coupling factors that participate in the sustained second phase of the secretory response [12]. To date, the putative impact of the $\mathrm{A} 3243 \mathrm{G}$ mutation on insulin secretion in diabetic patients has been examined in only a few studies, where carriers of the mutation exhibited markedly reduced insulin release in intravenous glucose tolerance tests and hyperglycaemic clamps compared to non-carriers [13-15]. It was hypothesised that a defect in glucose recognition would be an early possible primary abnormality in carriers of the mutation [13]. It has been suggested that impaired mitochondrial metabolism in cells of individuals carrying mutations in the mitochondrial genome might predispose to beta cell dysfunction, although this hypothesis has not been tested [16]. The current hypothesis suggests that the mitochondrial A3243G mutation could result in mitochondrial impairment leading to beta cell dysfunction. Therefore, it is crucial to investigate the consequences of this mutation on parameters highly relevant for beta cell metabolism-secretion coupling.

Direct investigation of beta cell functions carrying specific mtDNA mutations was technically impossible since (1) unlike genomic DNA, mtDNA manipulations are not feasible; (2) generation of cybrids with human beta cells was ruled out as human beta cell lines were unavailable at the time of our study; and (3) it is not possible to mix human mitochondria with rodent genomic DNA (e.g. with existing rodent beta cell lines). Accordingly, we studied patient-derived mitochondria in a human osteosarcoma cell line. Specifically, cells obtained from the parental human cell line 143B and depleted of mtDNA $\left(\mathrm{rho}^{\circ}\right)$ were used as recipients for mtDNA from a patient with the A3243G mutation. The resulting clonal cell lines contained either exclusively patient-derived mutated mtDNA (M12 cells) or wild-type mtDNA (W20 cells) from the same patient [7]. In these cells, key metabolic parameters in response to glucose versus the mitochondrial substrate pyruvate were measured.

\section{Materials and methods}

Cell culture

We used clonal cybrid cell lines derived from mtDNA-free $\rho^{\circ}$ cells replenished with M12 or W20 following cytosolic hybrid-based transformation [7]. The cybrid cell lines 143B. $\mathrm{TK}^{-}$(143B), $\beta \rho^{\circ}-3\left(\mathrm{rho}^{\circ}\right)$, W20, and M12 were cultured in DMEM (Gibco Invitrogen, Scotland, UK) containing $4.5 \mathrm{mg} / \mathrm{ml}$ of glucose and supplemented with $110 \mu \mathrm{g} / \mathrm{ml}$ pyruvate, $50 \mu \mathrm{g} / \mathrm{ml}$ uridine, $5 \%$ heat-inactivated FCS and antibiotics. The cells were routinely analysed for the presence of mutated mtDNA by PCR using total DNA [7]. For experiments, cells were seeded in 24-well plates and cultured 3 to 4 days before use. Reagents commonly used for the experiments were from Sigma-Aldrich (Buchs, Switzerland).

\section{Glucose metabolism and lactate production}

Glucose utilisation and oxidation were measured in cybrid cells essentially as previously described [17]. For glucose utilisation, cells were incubated for $10 \mathrm{~min}$ in KRB bicarbonate HEPES buffer (KRBH) containing in mmol/l: $135 \mathrm{NaCl}, 3.6 \mathrm{KCl}, 10$ HEPES (pH 7.4), $5 \mathrm{NaHCO}$, 0.5 $\mathrm{NaH} 2 \mathrm{PO} 4,0.5 \mathrm{MgCl} 2,1.5 \mathrm{CaCl}$, and supplemented with $5 \mathrm{mmol} / \mathrm{l}$ glucose traced with $\mathrm{D}-\left[5-{ }^{3} \mathrm{H}\right]$ glucose (final specific activity $14.8 \mathrm{MBq} / \mathrm{mmol}$ ), then stopped on ice. Supernatants were collected, centrifuged to remove detached cells, and ${ }^{3} \mathrm{H}_{2} \mathrm{O}$ separated from D- $\left[5-{ }^{3} \mathrm{H}\right]$ glucose using Dowex columns. For glucose oxidation, cells were incubated for $1 \mathrm{~h}$ in KRBH containing $5 \mathrm{mmol} / 1$ glucose traced with D-[14-C(U)]glucose (final specific activity $1.85 \mathrm{MBq} / \mathrm{mmol}$ ), then stopped by $\mathrm{HCl}$ addition before trapping of $\mathrm{CO}_{2}$ overnight in papers soaked with phenylthylamine:methanol (1:1). Respective ${ }^{3} \mathrm{H}_{2} \mathrm{O}$ and ${ }^{14} \mathrm{CO}_{2}$ productions were counted in a liquid scintillation counter 
(LS6500: Beckman Instruments, Palo Alto, CA, USA). Proteins were determined and glucose utilisation and oxidation expressed as nmol per $\mathrm{mg}$ protein per hour. The concentration of $5 \mathrm{mmol} / \mathrm{l}$ glucose for stimulations was selected throughout the study according to the dose response exhibited by these cells. Metabolic parameters were measured following cell preincubation in glucose-free medium for $2 \mathrm{~h}$.

Cybrid cells were cultured in 24-well plates in complete culture medium for $48 \mathrm{~h}$. Afterwards, culture medium serum was reduced from 5 to $1 \%$ and, after $48 \mathrm{~h}$ of culture, media were collected to measure lactate release. Lactate concentrations were determined as described [17].

\section{Cellular reactive oxygen species}

Cellular reactive oxygen species (ROS) were measured after cell preincubation in glucose-free or glucose $10 \mathrm{mmol} / 1$ medium for $6 \mathrm{~h}$ in a 24 -well plate. The cells were then incubated in glucose-free KRBH containing $10 \mu \mathrm{mol} / \mathrm{l}$ of the ROS-sensitive probe CM$\mathrm{H}_{2}$ DCFDA (Molecular Probes, Eugene, OR, USA) for 20 min. Quantification of CM- $\mathrm{H}_{2}$ DCFDA fluorescence was estimated as the slope normalised for protein content. Fluorescence was monitored with excitation and emission filters set at $485 \mathrm{~nm}$ and $520 \mathrm{~nm}$, respectively, in a platereader fluorimeter (Fluostar Optima; BMG Labtechnologies, Offenburg, Germany).

\section{Quantitative real-time PCR}

Total RNA was extracted using a kit (RNeasy Mini; Qiagen, Hilden, Germany) and $2 \mu \mathrm{g}$ RNA were converted into cDNA as previously described [18]. Primers for the reference genes beta-actin, copper zinc superoxide dismutase (CuZnSOD, also known as SOD1) and manganese superoxide dismutase $(M n S O D$, also known as SOD2) were designed using Primer Express (Applied Biosystems, Foster City, CA, USA). The primer sequences were: hCuZnSOD: forward 5'-CAGGGCATCATCAATTTCGA3', reverse 5'-CCATGCAGGCCTTCAGTCA-3'; hMnSOD: forward 5'-GCTTGTCCAAATCAGGATCCA3', reverse 5'-TAGTAAGCGTGCTCCCACACA-3'; hbetaactin: forward 5'-GACAGGATGCAGAAGGAGAT TACT-3', reverse 5'-TGATCCACATCTGCTGGAAGGT3'. Quantitative RT-PCR was performed using an sequence detection system (ABI 7000; Applied-Biosystems) and PCR products were quantified fluorometrically using the SYBR Green Core Reagent kit (Stratagene, La Jolla, CA, USA). Sod 1 and Sod 2 mRNA values were normalised for beta-actin gene. Experiments were performed in triplicate for each cell type.
$\mathrm{NAD}(\mathrm{P}) \mathrm{H}$ measurements and mitochondrial membrane potential

$\mathrm{NAD}(\mathrm{P}) \mathrm{H}$ levels were measured in attached cells as described [19]. Cells were placed in a plate reader fluorimeter at $37^{\circ} \mathrm{C}$ with automated injectors for test compounds and stimulated as indicated following stabilisation of the signal for $10 \mathrm{~min}$ in glucose/pyruvate-free KRBH. Maximal fluorescence changes were recorded after adding a mixture of $5 \mu \mathrm{mol} / \mathrm{l}$ rotenone (electron transport chain complex-1 inhibitor) plus $2 \mu \mathrm{mol} / 1$ antimycin-A (electron transport chain complex-3 inhibitor).

The mitochondrial membrane potential $\left(\Delta \Psi_{\mathrm{m}}\right)$ was monitored as fluorescence in cells loaded for $20 \mathrm{~min}$ with $10 \mu \mathrm{g} / \mathrm{ml}$ rhodamine-123 as described [19]. Glucose $(5 \mathrm{mmol} / \mathrm{l})$ or pyruvate $(1 \mathrm{mmol} / \mathrm{l})$ and the protonophore carbonyl cyanide $p$-trifluoromethoxyphenylhydrazone (FCCP, $1 \mu \mathrm{mol} / \mathrm{l}$ ) were added at the indicated times.

Cytosolic ATP levels and total cellular ATP content

Cytosolic ATP levels were monitored in cybrid cells expressing the ATP-sensitive bioluminescent probe luciferase, 1 day after transduction with the specific AdCAG-Luc viral construct $[20,21]$, in luminometer plate-reader as described [19]. After $5 \mathrm{~min}$ in glucosefree $\mathrm{KRBH}$, cells were stimulated with $5 \mathrm{mmol} / \mathrm{l}$ glucose or $1 \mathrm{mmol} / \mathrm{l}$ pyruvate, and $2 \mathrm{mmol} / 1 \mathrm{NaN}_{3}$ were added at the end as a mitochondrial poison. Total ATP contents were also determined in cybrid cell lysates after $5 \mathrm{~min}$ glucose $(5 \mathrm{mmol} / \mathrm{l})$ or pyruvate $(1 \mathrm{mmol} / \mathrm{l})$ stimulation, using an ATP bioluminescent assay kit (Roche, Mannheim, Germany).

\section{Calcium concentration measurements}

Cytosolic calcium changes were monitored as ratiometric measurements of Fura-2 fluorescence from cells placed in a plate-reader fluorimeter as described [22]. To measure mitochondrial calcium, cells cultured in 24-well plates for 3 to 4 days were transduced with AdCA-mAeq adenovirus enabling expression of the $\mathrm{Ca}^{2+}$-sensitive photoprotein aequorin targeted to the mitochondria. Twenty hours after viral treatment, cells were loaded with the aequorin prosthetic group coelenterazine $(2.5 \mu \mathrm{mol} / \mathrm{l})$ in $\mathrm{KRBH}$ for $1 \mathrm{~h}$ and luminescence was monitored in the plate-reader luminometer [19].

\section{Statistical analysis}

Unless otherwise indicated, data are means \pm SE for at least three independent experiments. Differences between groups were assessed by the Student's $t$-test. 

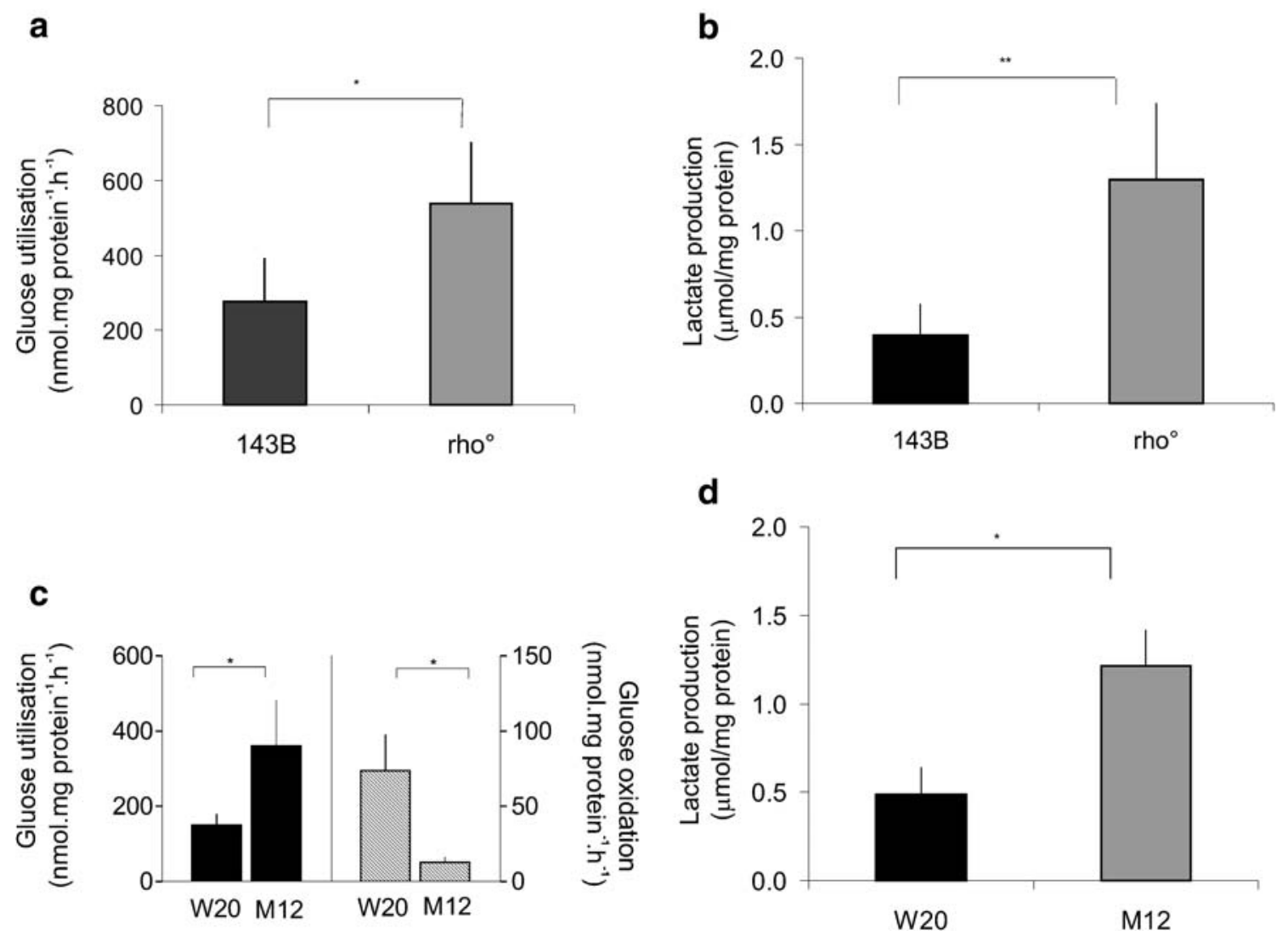

Fig. 1 Glucose utilisation and lactate production in cybrid cells. mtDNA-depleted $\left(\mathrm{rho}^{\circ}\right)$ cells were compared to parental 143B cells (a, b) and mtDNA mutant (M12) cells to wild type (W20) cells (c, d). Glucose $(5 \mathrm{mmol} / \mathrm{l})$ utilisation $(\mathbf{a}, \mathbf{c})$ was measured as the formation of ${ }^{3} \mathrm{H}_{2} \mathrm{O}$ from $\mathrm{D}-\left[5^{3} \mathrm{H}\right]$ glucose over a 10 -min stimulation period and

\section{Results}

Glucose metabolism and lactate production

Glucose utilisation, i.e. glycolytic rate, was measured as the formation of ${ }^{3} \mathrm{H}_{2} \mathrm{O}$ from $\mathrm{D}-\left[5-{ }^{3} \mathrm{H}\right]$ glucose at the glycolysis enolase step (Fig. 1). On $5 \mathrm{mmol} / 1$ glucose stimulation, rho $^{\circ}$ cells consumed 1.9 times more glucose than parental 143B cells $(p<0.05)$. This elevated glucose utilisation was accompanied by acidification of the culture medium. Thus, after $48 \mathrm{~h}$ incubation in complete culture medium, rho $^{\circ}$ cells generated 3.3 times more lactate than 143B cells $(p<0.01)$ (Fig. 1b).

Analysis of cybrid cells showed a 2.8-fold increase $(p<0.05)$ of glucose utilisation in M12 versus W20 cells (Fig. 1c). Glucose oxidation in control W20 cells accounted for $49 \%$ of the glycolytic rate. Glucose oxidation was much lower in M12 than in W20 cells $(-83 \%, p<0.05)$ and accounted for only $3.5 \%$ of the glycolytic rate in M12 cells. Accordingly, lactate generation was elevated in M12 compared to W20 cells (2.5-fold, $p<0.05)$ (Fig. 1d). We have previously reported a marked increase in the ratio of

glucose oxidation (c) as the production of ${ }^{14} \mathrm{CO}_{2}$ from $\mathrm{D}[14-\mathrm{C}(\mathrm{U})]$ glucose over a 1-h incubation period. Lactate production $(\mathbf{b}, \mathbf{d})$ was determined in the media following a 48 -h culture period. Values are means $+\mathrm{SE}$ of four independent experiments $\left({ }^{*} p<0.05 ; * * p<0.01\right)$

lactate to pyruvate production by M12 cells [7], and together these data demonstrate that the $\mathrm{A} 3243 \mathrm{G}$ mutation renders cells highly glycolytic with preferred lactate release rather than pyruvate oxidation by mitochondria.

\section{Cellular ROS and SOD expression}

Cybrid cells were incubated in glucose-free or glucose $10 \mathrm{mmol} / 1 \mathrm{medium}$ for $6 \mathrm{~h}$ and intracellular ROS were measured using $\mathrm{CM}-\mathrm{H}_{2}$ DCFDA probe. We observed no significant differences in ROS generation between rho $^{\circ}$ and 143B cells (not shown).

In contrast, mutant M12 cells generated 2.1 times more intracellular ROS than W20 in the absence of glucose $(p<0.05)$ (Fig. 2a). However, no significant differences in ROS generation were found between mutant M12 and W20 cells upon glucose $(10 \mathrm{mmol} / \mathrm{l})$ stimulation (not shown). In M12 cells incubated with $10 \mathrm{mmol} / 1$ glucose, intracellular ROS levels fell by $32 \%(p<0.005)$ against the glucosedeprived state (Fig. 2b).

Expression of key enzymes modulating cellular ROS at the cytosolic (SOD1) and the mitochondrial (SOD2) levels 


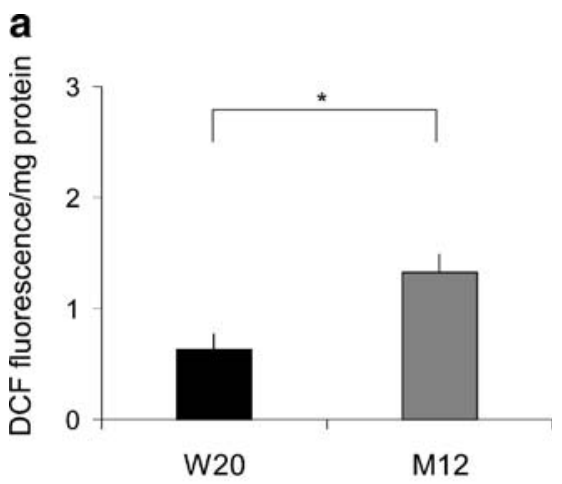

b
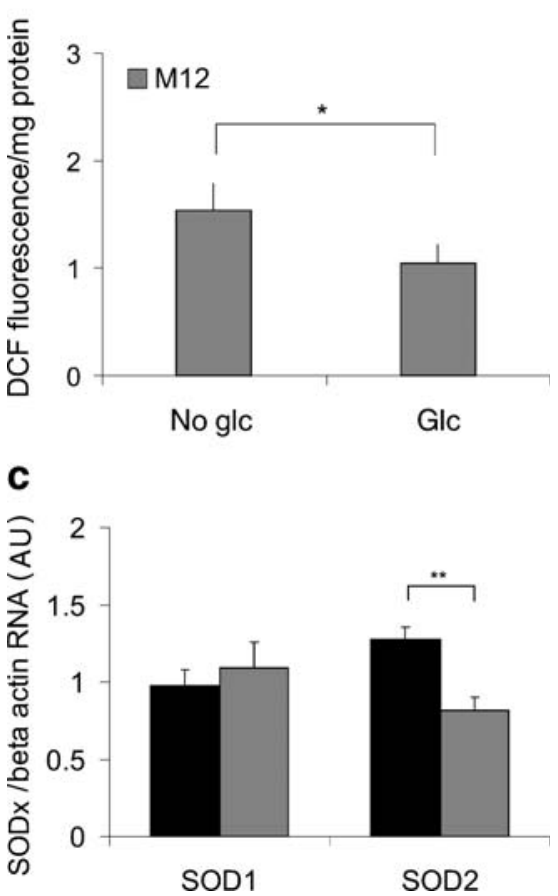

Fig. 2 Reactive oxygen species (ROS) in cybrid cells. ROS production was measured using the probe $\mathrm{CM}-\mathrm{H}_{2}$ DCFDA following $6 \mathrm{~h}$ of incubation in the absence or presence of glucose. a W20 and M12 ROS levels with no glucose. M12 ROS levels (b) in the absence (No glc) or presence (Glc) of glucose $10 \mathrm{mmol} / \mathrm{l}$. Values are means + SE of three independent experiments $\left({ }^{*} p<0.05\right)$. c SOD1 and SOD2 mRNA levels in W20 (dark bars) and M12 (shaded bars) cells were normalised for beta-actin expression. Values in arbitrary units $(A U)$ are means $+\mathrm{SE}$ of three independent experiments done in triplicate $(* * p<0.01)$

was analysed by quantitative RT-PCR. Mitochondrial SOD2 mRNA levels were $1.36 \pm 0.02$ fold higher in W20 than in M12 cells $(p<0.01)$. No difference was seen in cytosolic SOD1 mRNA levels between W20 and M12 cells (Fig. 2c).

\section{NAD(P)H levels}

NAD(P)H levels are predominantly determined by mitochondria in healthy cells. Glucose $(5 \mathrm{mmol} / \mathrm{l})$ stimulation raised $\mathrm{NAD}(\mathrm{P}) \mathrm{H}$ levels in control W20 and parental 143B cells. Conversely, glucose failed to efficiently promote $\mathrm{NAD}(\mathrm{P}) \mathrm{H}$ generation in $\mathrm{M} 12$ and rho $^{\circ}$ cells (Fig. 3a,b). Average NAD $(\mathrm{P}) \mathrm{H}$ levels during the $5 \mathrm{~min}$ after glucose addition were $56 \%$ lower in M12 than in W20 cells $(p<0.0001)$, and $51 \%$ lower in rho $^{\circ}$ than in $143 \mathrm{~B}$ cells $(p<0.0002)$.

The mitochondrial substrate pyruvate $(1 \mathrm{mmol} / \mathrm{l})$ raised $\mathrm{NAD}(\mathrm{P}) \mathrm{H}$ levels in $\mathrm{W} 20$ and 143B cells, whereas in M12 and rho ${ }^{\circ}$ cells it lowered NAD(P)H (Fig. 3c,d). Blockade of the respiratory chain at complex-1 $(5 \mu \mathrm{mol} / \mathrm{l}$ rotenone $)$ and complex-3 ( $2 \mu \mathrm{mol} / 1$ antimycin A), added to maximally increase mitochondrial NADH, further enhanced autofluorescence, revealing the mitochondrial origin of the signal. These results show that mtDNA mutant cells exhibit deranged redox state and are unable to elevate $\mathrm{NAD}(\mathrm{P}) \mathrm{H}$ above basal levels.

Mitochondrial membrane potential

In control W20 and 143B cells, the protonophore FCCP dissipated, thereby revealing, established resting $\Delta \Psi_{\mathrm{m}}$. In contrast, FCCP addition in mutant $\mathrm{M} 12$ and $\mathrm{rho}^{\circ}$ cells showed that resting $\Delta \Psi_{\mathrm{m}}$ in these cells was only negligible (Fig. 4a). Upon glucose $(5 \mathrm{mmol} / \mathrm{l})$ stimulation, hyperpolarisation was observed in the four cell lines.

Interestingly, $\Delta \Psi_{\mathrm{m}}$ was also built up on glucose stimulation in $\mathrm{M} 12$ and $\mathrm{rho}^{\circ}$ cells, although responses were slower than in respective controls (Fig. 4b,c). Upon pyruvate $(1 \mathrm{mmol} / \mathrm{l})$ stimulation, the paradoxical effect of a first-phase depolarisation was observed in 143B cells (Fig. 4d). This effect has been previously attributed to pyruvate uptake by mitochondria and is followed by the expected sustained hyperpolarisation [18]. Unlike glucose stimulation, the mitochondrial substrate pyruvate did not increase $\Delta \Psi_{\mathrm{m}}$ in $\mathrm{M} 12$ or rho $^{\circ}$ cells (Fig. $4 \mathrm{~d}$ ).

Next, using inhibitors of the ATP synthase and of the adenine nucleotide translocator (ANT), we investigated the mechanisms underlying the delayed glucose-induced mitochondrial hyperpolarisation in $\mathrm{M} 12$ and rho ${ }^{\circ}$ cells. Previous studies attributed the build up of $\Delta \Psi_{\mathrm{m}}$ in rho ${ }^{\circ}$ cells to reverse activities of ATP synthase and ANT, thereby favouring the electrogenic exchange of $\mathrm{ATP}^{4-}$ for $\mathrm{ADP}^{3-}$ $[2,23]$. However, this effect has not yet been characterised in cells containing mtDNA mutations. The ATP synthase $\mathrm{F}_{0}$ section is composed of two mtDNA encoded subunits and is not fully active in mtDNA mutant cell lines or in rho ${ }^{\circ}$ cells $[2,23]$. In contrast, ATP synthase $\mathrm{F}_{1}$ section activity is preserved in rho $^{\circ}$ cells where it may function in the reverse mode, i.e. as an ATPase. To pinpoint the origin of glucoseinduced $\Delta \Psi_{\mathrm{m}}$ in M12 cells, specific blockers of $\mathrm{F}_{0}$ and $\mathrm{F}_{1}$ ATPase subunits were used: oligomycin $(2 \mu \mathrm{g} / \mathrm{ml})$ and aurovertin (30 or $60 \mu \mathrm{mol} / \mathrm{l})$, respectively. Oligomycin did 
a
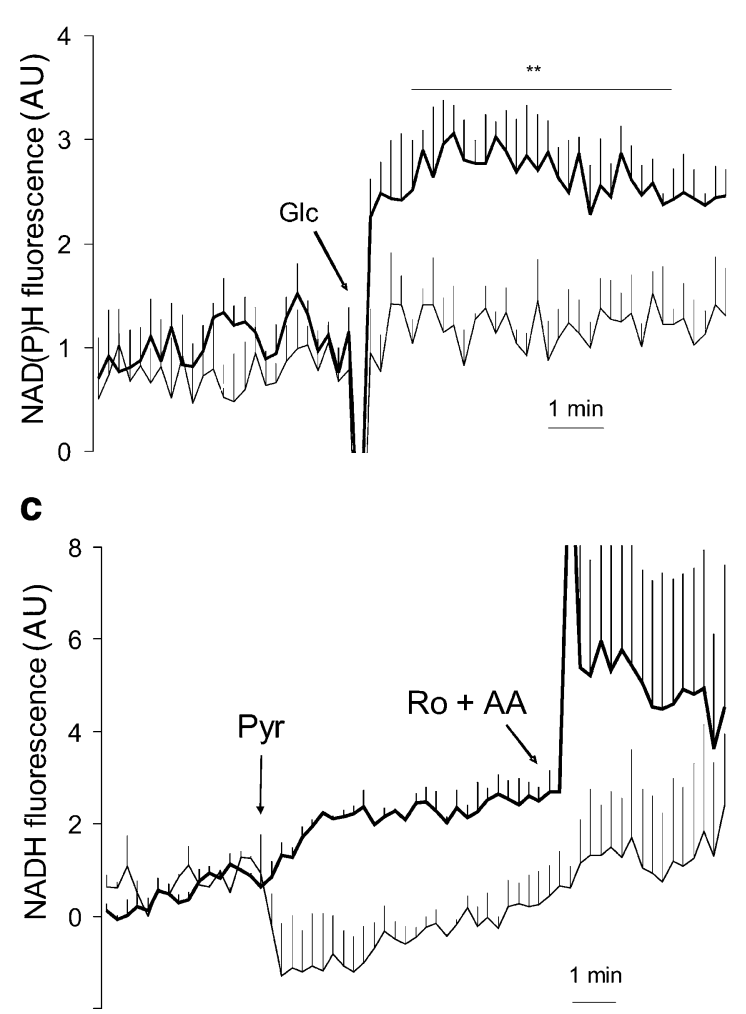

Fig. 3 Effects of glucose $(G l c)$ and pyruvate $(P y r)$ on $\mathrm{NAD}(\mathrm{P}) \mathrm{H}$ levels in cybrid cells. W20 (bold lines) and M12 (thin lines) cells (a, c) or (b,d) 143B (bold lines) and $\mathrm{rho}^{\circ}$ (thin lines) cells were kept in glucose-free $\mathrm{KRBH}$ for the first $10 \mathrm{~min}$ and then stimulated with $5 \mathrm{mmol} / \mathrm{l}$ glucose $(\mathbf{a}, \mathbf{b})$ or $1 \mathrm{mmol} / \mathrm{l}$ pyruvate $(\mathbf{c}, \mathbf{d})$ as indicated by the

not prevent glucose-evoked $\Delta \Psi_{\mathrm{m}}$ in M12 cells and rho ${ }^{\circ}$ cells (data not shown). However, aurovertin $(60 \mu \mathrm{mol} / \mathrm{l})$ in combination with bongkrekic acid $(10 \mu \mathrm{mol} / \mathrm{l})$, an ANT inhibitor acting on the matrix side, fully prevented glucoseinduced $\Delta \Psi_{\mathrm{m}}$ establishment in M12 and rho ${ }^{\circ}$ cells (Fig. 5a, b). These results indicate that glucose-induced mitochondrial hyperpolarisation observed in M12 cells was generated by combined reverse activities of ANT and ATP synthase.

\section{Cellular ATP levels}

In control W20 and parental 143B cells, glucose $(5 \mathrm{mmol} / \mathrm{l})$ stimulation resulted in sustained elevation of cytosolic ATP levels, which were disrupted by adding the mitochondrial poison $\mathrm{NaN}_{3}$ (Fig. 6a,c). In mutant M12 and rho ${ }^{\circ}$ cells, ATP generation upon glucose stimulation was only transient, as a drop in ATP levels was observed before $\mathrm{NaN}_{3}$ addition (Fig. 6b,d). The mitochondrial substrate pyruvate $(1 \mathrm{mmol} / \mathrm{l})$ augmented cytosolic ATP levels in W20 and 143B cells (Fig. 6a,c), but not in $\mathrm{M} 12$ and rho $^{\circ}$ cells (Fig. 6b,d). This shows that ATP generation in M12 cells, b

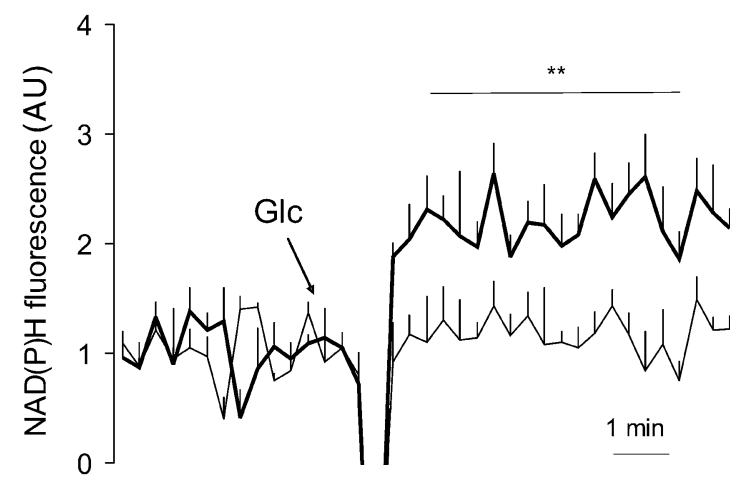

d

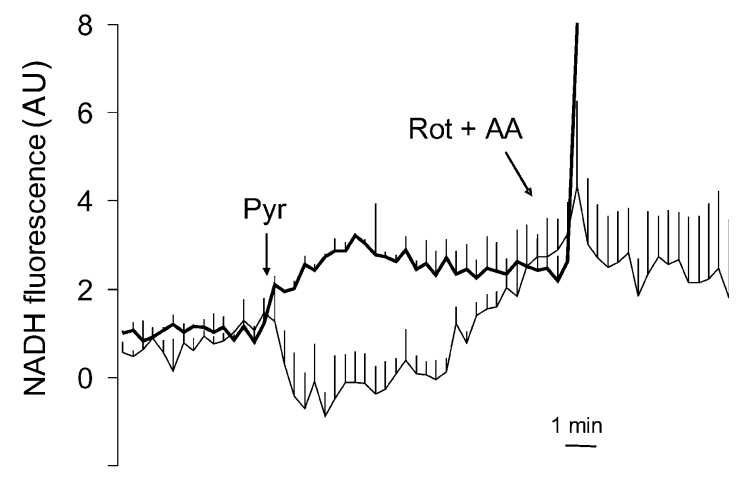

arrows. In order to maximally elevate mitochondrial NADH levels, a mixture of inhibitors of complex-1 (5 $\mu \mathrm{mol} / 1$ rotenone; Ro) and complex-3 ( $2 \mu \mathrm{mol} / 1$ antimycin A; AA) was added $10 \mathrm{~min}$ after pyruvate stimulation. Values in arbitrary units $(A U)$ are means $+\mathrm{SE}$ of three independent experiments $(* * p<0.001)$

as in rho ${ }^{\circ}$ cells, was exclusively dependent on glucose utilisation, with no contribution by mitochondria.

Upon pyruvate stimulation, an initial drop in ATP levels occurred in W20 and 143B cells before sustained ATP increase (Fig. 6a,c), an effect correlating with transient depolarisation of $\Delta \Psi_{\mathrm{m}}$ [18]. Measurements of total cellular ATP concentrations showed that pyruvate stimulation did not change ATP contents in M12 or rho ${ }^{\circ}$ cells, indicating the lack of ATP generation of mitochondrial origin in these cells (not shown).

Basal absolute ATP contents in rho ${ }^{\circ}$ and M12 cells were 222 and 100 times lower than in $143 \mathrm{~B}$ or W20 cells, respectively, i.e. $0.09 \pm 0.04\left(\mathrm{rho}^{\circ}\right), 0.17 \pm 0.08$ (M12), $20.0 \pm$ 4.2 (143B) and $17.2 \pm 4.0$ (W20) $\mathrm{nmol} \mathrm{ATP} / \mathrm{mg}$ protein (Fig. 7). Following 5 min glucose $(5 \mathrm{mmol} / \mathrm{l})$ stimulation, ATP contents in these cells were: $9.7 \pm 1.6\left(\mathrm{rho}^{\circ}\right), 12.5 \pm 2.0$ (M12), 24.0 5 5.1 (143B) and 20.7 \pm 5.8 (W20) nmol ATP/mg protein (Fig. 7). Therefore, the following fold increases in cellular ATP contents upon glucose stimulation were: 1.2fold (143B), 1.2-fold (W20), 108-fold $\left(\right.$ rho $^{\circ}$ ), and 74-fold (M12). ATP contents measured in $\mathrm{M} 12$ and rho $^{\circ}$ cells, before and after glucose stimulation, were consistent with 
Fig. 4 Mitochondrial membrane potential $\left(\Delta \Psi_{\mathrm{m}}\right)$ in cybrid cells. The four different cell lines (143B, rho $\left.{ }^{\circ}, \mathrm{W} 20, \mathrm{M} 12\right)$ were cultured in 24-well plates and $\Delta \Psi_{\mathrm{m}}$ was monitored as rhodamine-123 (Rh-123) fluorescence. a After $20 \mathrm{~min}$ of stabilisation, the amplitude of resting $\Delta \Psi_{\mathrm{m}}$ was estimated following complete dissipation of the proton gradient by the addition of $1 \mu \mathrm{mol} / \mathrm{l}$ of the protonophore carbonyl cyanide $p$-trifluoromethoxyphenylhydrazone $(F C C P)$. For glucose $(G l c)$ $(\mathbf{b}, \mathbf{c})$ and pyruvate $(P y r)$

(d) responses, cells were kept in nutrient-free $\mathrm{KRBH}$ for the first $10 \mathrm{~min}$ before stimulation with $5 \mathrm{mmol} / \mathrm{l}$ glucose or $1 \mathrm{mmol} /$ 1 pyruvate. Ten minutes after stimulation, $\Delta \Psi_{\mathrm{m}}$ was collapsed by adding $1 \mu \mathrm{mol} / 1 \mathrm{FCCP}$.

Values in arbitrary units $(A U)$ are means + SE of three to eight independent experiments

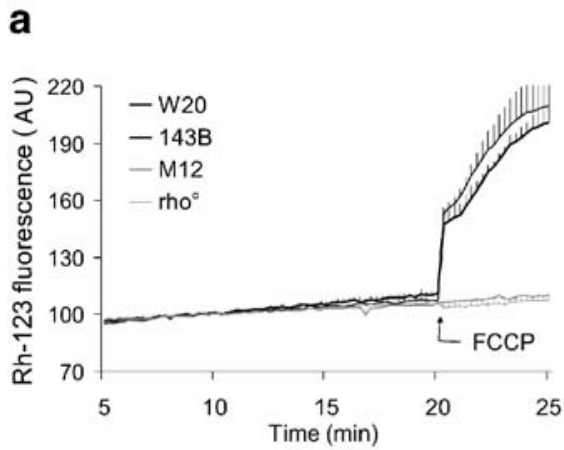

C

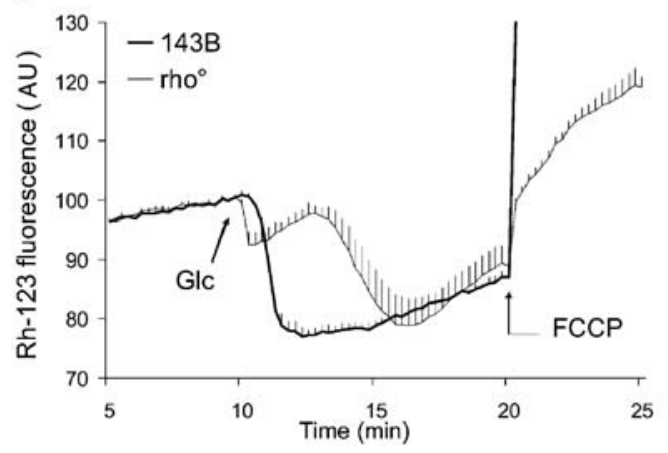

b

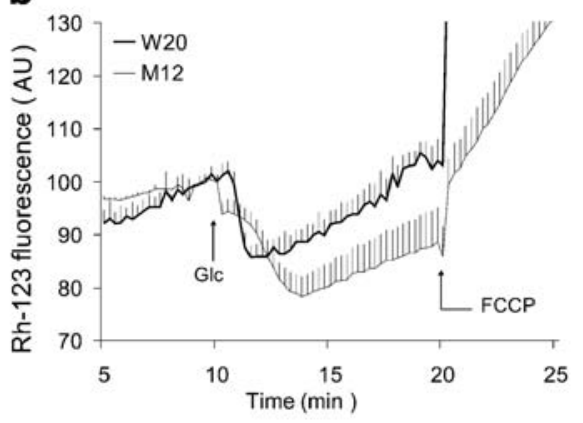

d

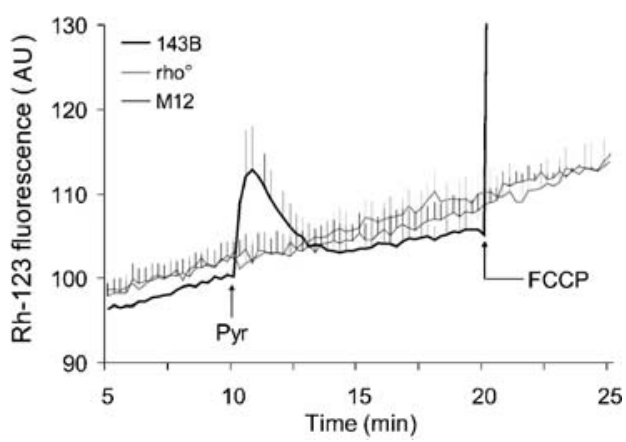

the kinetics of cytosolic ATP levels. These results show that A3243G mutation renders cells exclusively dependent on glycolysis for the supply of cellular ATP.

\section{Calcium concentrations}

Cytosolic calcium rises were evoked by adding the inositol1,4,5-triphosphate agonist histamine (100 $\mu \mathrm{mol} / \mathrm{l})$, triggering calcium mobilisation from the endoplasmic reticulum. Histamine induced calcium peaks of similar amplitudes in M12 and W20 cells. However, return to basal levels during the second phase was markedly delayed in mutant M12, resulting in elevated cytosolic calcium load (Fig. 8a). Cytosolic calcium loads, determined for $2 \mathrm{~min}$ after the peak and expressed as the AUC, were 1.4-fold higher $(p<0.005)$ in M12 than in W20 cells.

Mitochondria participate in cellular calcium homeostasis through their ability to buffer and redistribute calcium. Mitochondrial calcium levels were monitored in M12 and W20 cells expressing the calcium-sensitive photoprotein aequorin targeted to mitochondria. Qualitatively, M12 and control W20 cells exhibited similar mitochondrial calcium patterns in terms of histamine responses However, calcium levels were shifted down in M12 cells, indicating reduced calcium uptake by mitochondria (Fig. 8b).

\section{Discussion}

This study demonstrates that the diabetes-associated A3243G mutation in the mitochondrial genome impairs the key metabolic events required for cellular functions, such as metabolism-secretion coupling. Due to technical limitations, the study was performed in non-beta cells, i.e. in an osteosarcoma cell line. A recently established human beta cell line [24] might enable the establishment of beta cell cybrids in future. To investigate the putative link between the specific mtDNA mutation A3243G and cellular metabolism, it was crucial to study side-by-side cybrid cells carrying either mutant or wild type mtDNA obtained from the same patient. We observed that the A3243G mutation induced a shift to dominantly glycolytic metabolism, as M12 cells consumed more glucose and produced more lactate than W20 cells, while glucose oxidation to $\mathrm{CO}_{2}$ was reduced. The mitochondrial mutation not only affected mitochondrial metabolism, but also modified cytosolic calcium homeostasis.

In response to glucose addition, levels of reducing equivalents in the form of $\mathrm{NAD}(\mathrm{P}) \mathrm{H}$ were not further elevated in mutant M12 cells compared with basal levels. In contrast, sustained increases in $\mathrm{NAD}(\mathrm{P}) \mathrm{H}$ levels were observed upon glucose stimulation in control W20 cells. These results reflect the impact of this mutation on the electron transport chain. Indeed, complex-1 activity in M12 cells is known to be diminished in comparison to W20 cells [7], a finding confirmed in this study by the lack of responses to complex-1 inhibitor rotenone. The associated deficient $\mathrm{NADH}$ reoxidation would lead to mitochondrial $\mathrm{NADH}$ accumulation, slowing down reactions coupled to $\mathrm{NADH}$ generation in the citric acid cycle. The metabolic consequences would be a switch to anaerobic glucose 
a

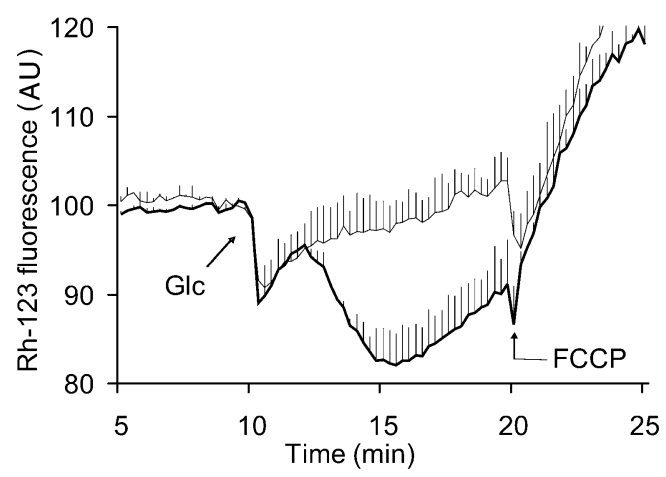

b

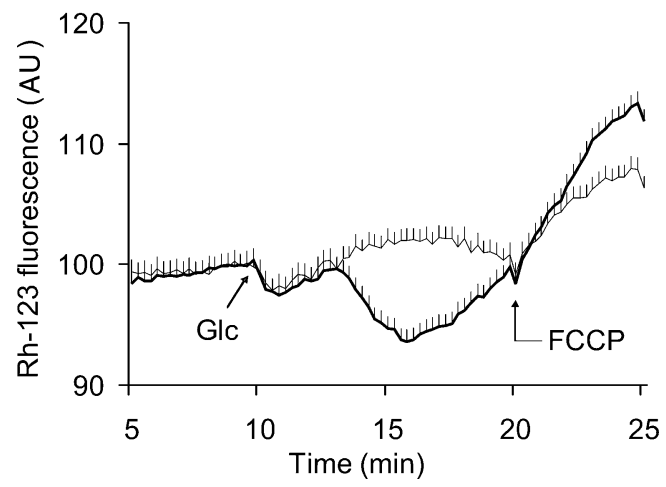

Fig. 5 Glucose-induced mitochondrial membrane potential $\left(\Delta \Psi_{\mathrm{m}}\right)$ in mutant M12 cells (a) and mtDNA-deficient $\left(\mathrm{rho}^{\circ}\right)$ cells $(\mathbf{b})$. Cells were cultured in 24-well plates and $\Delta \Psi_{\mathrm{m}}$ was monitored as rhodamine-123 $(R h-123)$ fluorescence (arbitrary units $[A U])$. Cells were preincubated for $30 \mathrm{~min}$ before the experiment in glucose-free $\mathrm{KRBH}$ without (control, bold lines) or with a mixture containing $60 \mu \mathrm{mol} / 1$ aurovertin and $10 \mu \mathrm{mol} / 1$ bongkrekic acid $(\mathrm{Bo}+\mathrm{Au}$, thin lines). During the recordings, cells were kept in the same solutions for $10 \mathrm{~min}$ before stimulation with $5 \mathrm{mmol} / \mathrm{l}$ glucose $(G l c)$. Ten minutes after stimulation, $\Delta \Psi_{\mathrm{m}}$ was collapsed by adding $1 \mu \mathrm{mol} / 1$ carbonyl cyanide $p$-trifluoromethoxyphenylhydrazone $(F C C P)$. Traces are one representative of at least three independent experiments

utilisation accompanied by increased lactate generation, both observed in the present study. Interestingly, NADH levels were transiently reduced in mutant M12 cells upon pyruvate stimulation, an effect attributed to favoured metabolism through lactate dehydrogenase rather than mitochondrial pathway.

Established $\Delta \Psi_{\mathrm{m}}$, as measured in control W20 cells, was absent in mutant M12 cells, revealing that the A3243G mutation carried by $\mathrm{M} 12$ cells severely impaired the electron transport chain activity, in accordance with reduced activities of mtDNA-encoded complexes 1, 3, and 4 of the electron transport chain in M12 cells [7]. Interestingly, some mitochondrial hyperpolarisation was observed in M12 cells upon glucose stimulation, albeit delayed in comparison to control W20 cells. Our data indicate that this effect results from inverted activities of ANT, in this case importing cytosolic ATP, and from ATP synthase working as ATPase, i.e. hydrolysing instead of synthesising ATP [2].
This metabolic adaptation was demonstrated here by inhibiting the translocator and the ATPase F1 subunit, thereby abolishing M12 mitochondrial hyperpolarisation. Even when not coupled to oxidative phosphorylation, the build up of some $\Delta \Psi_{\mathrm{m}}$ is necessary for import of nuclear encoded proteins in mitochondria, where major metabolic pathways have to interact. Therefore, these mutant cells rely on glycolysis-derived ATP that enters mitochondria to be hydrolysed to ADP $+\mathrm{H}^{+}$. ADP is then exported from the mitochondria and the overall process produces net negative charges in the mitochondrial matrix, promoting hyperpolarisation. Upon pyruvate stimulation, no build up of $\Delta \Psi_{\mathrm{m}}$ was seen in M12 cells, indicating the absolute requirement of glycolytic pathway.

Mutant M12 cells exhibited severe reduced ATP contents compared with W20 cells. Surprisingly, we observed massive increases in ATP levels in M12 cells upon glucose stimulation, although these were only transient and barely approaching basal absolute ATP levels in control W20 cells. In M12 cells, the lack of response to pyruvate stimulation and to azide-mediated inhibition showed the impairment of mitochondria as ATP generators, pointing to glycolysis as the source of cellular ATP. Together with the increased glycolytic rate, these results show a remarkable adaptation of cells with mutated mtDNA, enabling them to generate ATP at the expense of glucose-derived carbons in the form of lactate release. It is well known that such a phenotype dramatically impairs glucose-stimulated insulin secretion in beta cells.

Cytosolic $\mathrm{Ca}^{2+}$ rises evoked by histamine stimulation were immediate and of similar amplitudes in control W20 and mutant M12 cells. However, the second phase, corresponding to progressive return to basal levels, was prolonged in M12 cells. Scarce ATP supply in mutant M12 cells possibly would not suffice for efficient $\mathrm{Ca}^{2+}$ transfer into $\mathrm{Ca}^{2+}$ stores, i.e. the endoplasmic reticulum, by the sarco(endo)plasmic-reticulum $\mathrm{Ca}^{2+}$-ATPase pump. Depolarised mitochondria in M12 cells might also help impair $\mathrm{Ca}^{2+}$ buffering capacity of the cell. Accordingly, we measured lower mitochondrial $\mathrm{Ca}^{2+}$ concentrations in M12 than in W20 cells. Deranged $\mathrm{Ca}^{2+}$ homeostasis may vary according to specific mtDNA mutations. In cybrid cells with the T8356C mtDNA mutation, which is associated with myoclonic epilepsy with ragged-red fibres [25], mitochondrial $\mathrm{Ca}^{2+}$ homeostasis is also altered [26]. However, in contrast to A3243G cybrids, T8356C cells exhibit normal cytosolic $\mathrm{Ca}^{2+}$ responses. Such a difference might contribute to mtDNA-specific phenotypes.

Mitochondria are known to be the main source and target of intracellular ROS. The imbalance between excessive formation of ROS and limited antioxidant defences causes oxidative stress [27]. Only few studies have looked at ROS generation in cells with mtDNA mutations [28-30]. It is 
Fig. 6 Cytosolic ATP changes in cybrid cells. Cytosolic ATP levels were monitored as bioluminescence following luciferase expression in wild-type mtDNA W20 cells (a), mutant mtDNA M12 cells (b), parental 143B cells (c), and mtDNA-deficient rho ${ }^{\circ}$ cells $(\mathbf{d})$. Cells were kept in glucose-free $\mathrm{KRBH}$ for the first $5 \mathrm{~min}$ and then stimulated with $5 \mathrm{mmol} / 1$ glucose (black lines) or $1 \mathrm{mmol} / \mathrm{l}$ pyruvate (dark grey lines) for $10 \mathrm{~min}$ before abrogating ATP generation by the addition of $2 \mathrm{mmol} / 1 \mathrm{NaN}_{3}$.

Light grey lines, no glucose.

Values are means + SE of three to five independent experiments a

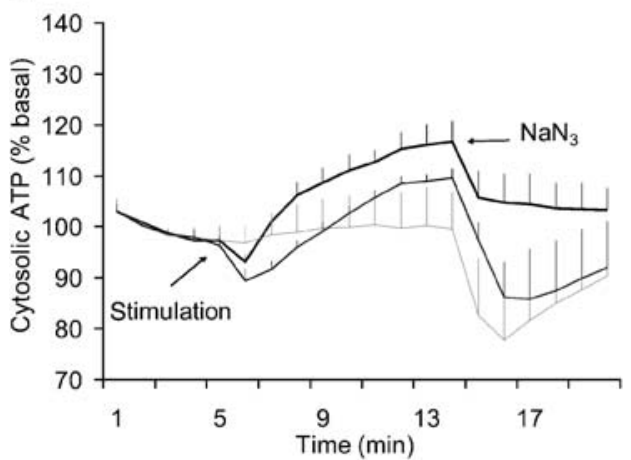

C

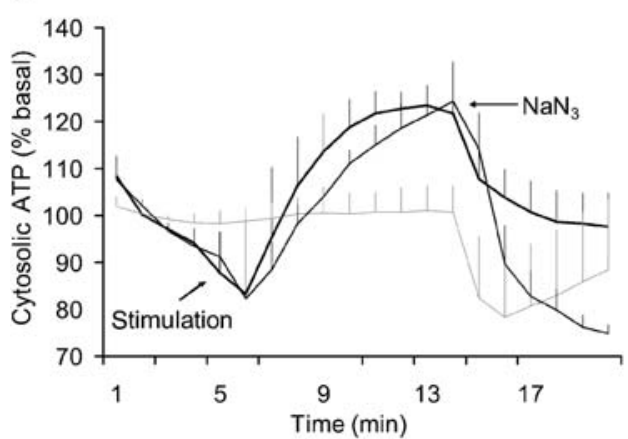

b

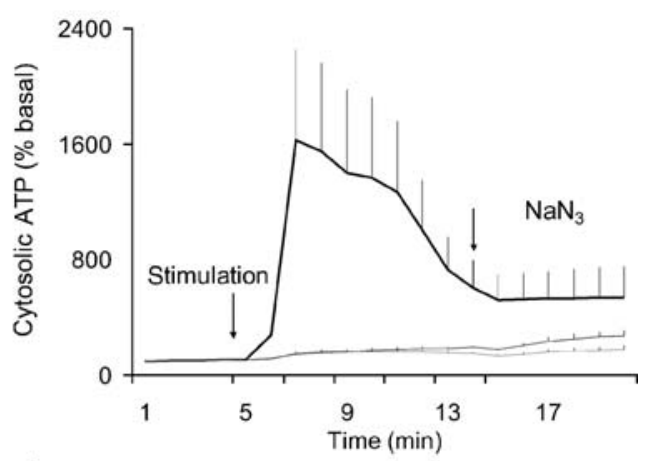

d

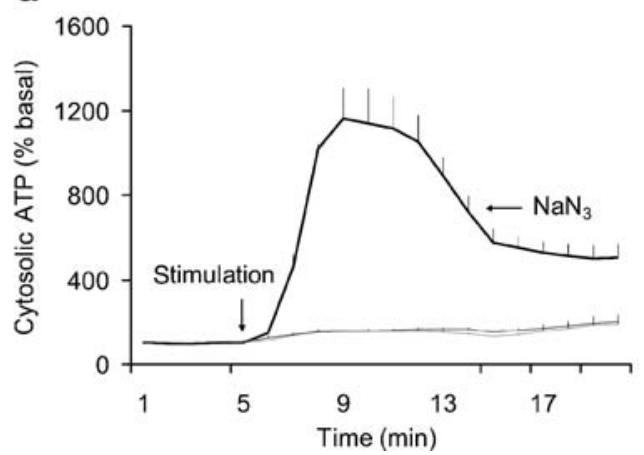

debatable whether mtDNA-depletion in rho ${ }^{\circ}$ cells generates more ROS than control cells would [31-34]. In the present study, the A3243G mutation was associated with higher intracellular ROS levels than control cells when glucose was removed from the medium. Addition of $10 \mathrm{mmol} / \mathrm{l}$ glucose

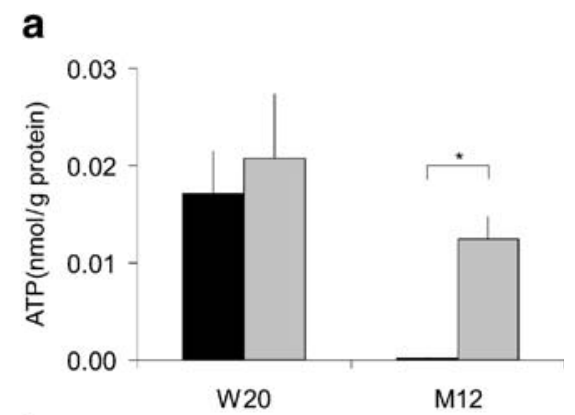

b

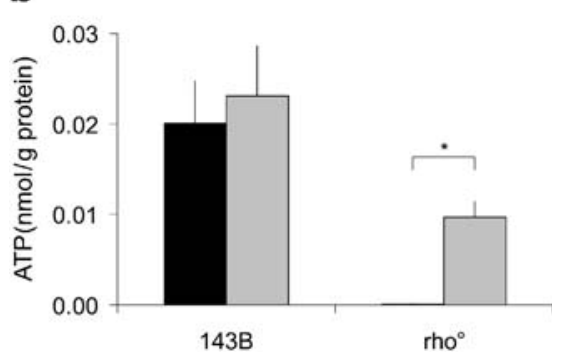

Fig. 7 Total ATP concentrations in cybrid cells. Total cellular ATP contents were determined in W20 and M12 cells (a) and 143B and rho $^{\circ}$ cells (b) cells following $5 \mathrm{~min}$ stimulation with $5 \mathrm{mmol} / 1$ glucose (grey bars), and normalised to cellular protein concentrations. Black bars, no glucose. Values are means $+\mathrm{SE}$ of three independent experiments $\left({ }^{*} p<0.05\right)$ lowered ROS levels in mutant M12 cells. Interestingly, cytotoxicity has been reported in the absence of glucose in cells carrying the A3243G mtDNA mutation [29]. Upon glucose deprivation, ATP synthesis, normally compensated by oxidative phosphorylation, is inefficient in mtDNA mutants (Fig. 7a) due to defective electron transport chain activity [7]. This lacking adaptability to other fuel sources would induce metabolic stress leading to inefficient detoxification pathways and increased ROS, as proposed recently [29]. Moreover, the observed lower expression of SOD2 in M12 mutant cells, similarly to LHON cybrids [35], would worsen the situation regarding ROS levels.

Upon glucose provision, ROS levels in M12 mutant cells fell to levels comparable with W20 control cells. It has been reported that cybrid cells carrying mutant mtDNA exhibit increased [28, 30] or unchanged [29] ROS levels. In a mouse model accumulating mtDNA mutations with age, amounts of ROS were normal, despite severe respiratory chain dysfunction [36]. Together, these findings indicate that ROS generation in cells with mtDNA mutations might not necessarily be altered pending compensatory energy state.

Numerous studies at the cellular level found that mitochondrial activation is crucial in beta cells for proper coupling of nutrient metabolism to insulin secretion [12]. At the clinical level, the importance of mitochondrial function in glucose homeostasis is revealed by diabetesassociated mutations in the mitochondrial genome $[4,5,10$, 37]. As the aetiology of diabetes may not be primarily 
a

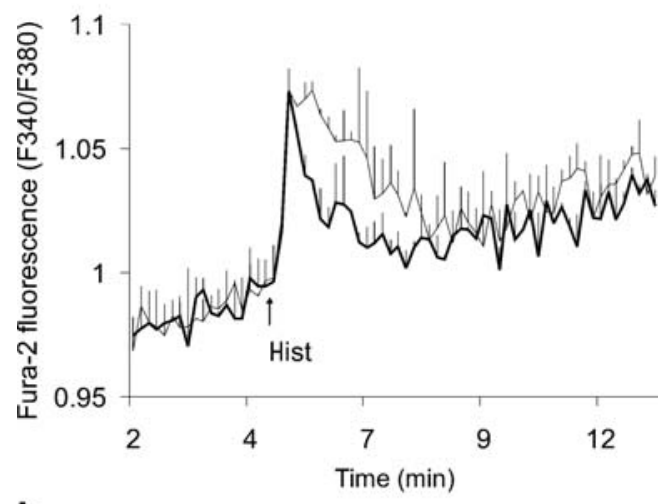

b

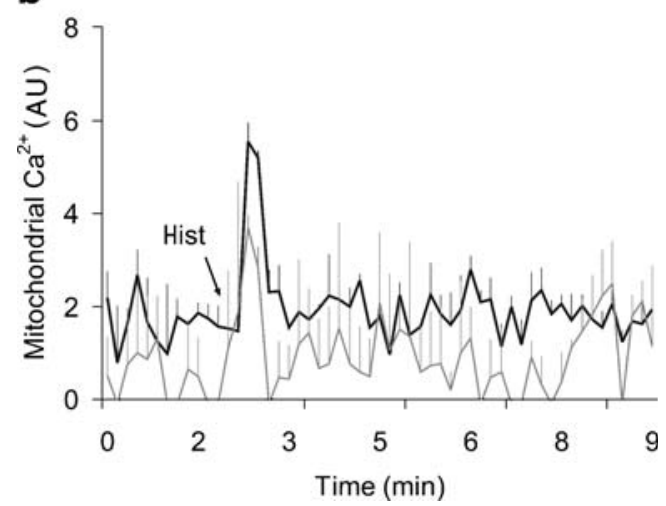

Fig. 8 Calcium concentrations in cybrid cells. Cytosolic and mitochondrial calcium concentrations in M12 (grey lines) and W20 (black lines) cells were monitored as Fura-2 fluorescence (a) and bioluminescence emitted by cells expressing the calcium-sensitive photoprotein aequorin targeted to mitochondria (b). Calcium rises were induced by $100 \mu \mathrm{mol} / \mathrm{l}$ histamine (Hist). Values are means $+\mathrm{SE}$ of three independent experiments. $A U$, arbitrary units

associated with beta cells, the putative link between mtDNA mutations and beta cell dysfunction remains hypothetical [16]. However, three indirect lines of evidence suggest such a relationship. First, patients carrying the A3243G mtDNA mutation exhibit lower insulin levels during a hyperglycaemic clamp than non-carriers, pointing to beta cell defect rather than peripheral insulin resistance $[13,15]$. In addition, individuals with Pearson or Kearns Sayre syndromes due to large deletions in mtDNA exhibit an insulin-deficient diabetes phenotype [38, 39]. Second, transgenic mice lacking expression of the mitochondrial genome specifically in beta cells are diabetic with poor islet insulin release in response to glucose [40]. Third, mitochondrial DNA-depleted cellular models are glucose-unresponsive and defective in mitochondrial function [41-43]. These models illustrate the fragility of nutrient-stimulated insulin secretion, caused primarily by defective mitochondrial metabolism. What is missing among these lines of evidence is a demonstration of the effects of the A3243G mtDNA mutation on cellular functions required for metabolism-secretion coupling. Our results show the dramatic consequences of such a patient-derived mutation on glucose-induced mitochondrial metabolism. Future studies should directly investigate the effects of the mutation on glucose-stimulated insulin secretion.

Acknowledgements We thank C. Bartley and G. Chaffard for technical expertise and G. Janssen for analysis of mtDNA mutation. This study was supported by the Leenaards Foundation (Lausanne) through a collaborative grant with Urs Ruegg. Support from the Swiss National Science Foundation, the Schmidheiny Foundation (Geneva), and the Max Cloetta Foundation (Zurich) is also acknowledged. The project was part of the Geneva Program for Metabolic Disorders.

\section{References}

1. Wallace DC (1999) Mitochondrial diseases in man and mouse. Science 283:1482-1488

2. Buchet K, Godinot C (1998) Functional F1-ATPase essential in maintaining growth and membrane potential of human mitochondrial DNA-depleted rho degrees cells. J Biol Chem 273:22983-22989

3. Kadowaki T, Kadowaki H, Mori Y et al (1994) A subtype of diabetes mellitus associated with a mutation of mitochondrial DNA. N Engl J Med 330:962-968

4. van den Ouweland JM, Lemkes HH, Ruitenbeek W et al (1992) Mutation in mitochondrial $t R N A($ Leu)(UUR) gene in a large pedigree with maternally transmitted type II diabetes mellitus and deafness. Nat Genet 1:368-371

5. Maechler P, Wollheim CB (2001) Mitochondrial function in normal and diabetic beta-cells. Nature 414:807-812

6. Dunbar DR, Moonie PA, Zeviani M, Holt IJ (1996) Complex I deficiency is associated with 3243G:C mitochondrial DNA in osteosarcoma cell cybrids. Hum Mol Genet 5:123-129

7. van den Ouweland JM, Maechler P, Wollheim CB, Attardi G, Maassen JA (1999) Functional and morphological abnormalities of mitochondria harbouring the $t R N A(L e u)(\mathrm{UUR})$ mutation in mitochondrial DNA derived from patients with maternally inherited diabetes and deafness (MIDD) and progressive kidney disease. Diabetologia 42:485-492

8. Maassen JA, Janssen GM, t Hart LM (2005) Molecular mechanisms of mitochondrial diabetes (MIDD). Ann Med $37: 213-221$

9. Lynn S, Borthwick GM, Charnley RM, Walker M, Turnbull DM (2003) Heteroplasmic ratio of the A3243G mitochondrial DNA mutation in single pancreatic beta cells. Diabetologia 46:296-299

10. Maassen JA, van Essen E, van den Ouweland JM, Lemkes HH (2001) Molecular and clinical aspects of mitochondrial diabetes mellitus. Exp Clin Endocrinol Diabetes 109:127-134

11. Rorsman P (1997) The pancreatic beta-cell as a fuel sensor: an electrophysiologist's viewpoint. Diabetologia 40:487-495

12. Maechler P (2002) Mitochondria as the conductor of metabolic signals for insulin exocytosis in pancreatic beta-cells. Cell Mol Life Sci 59:1803-1818

13. Velho G, Byrne MM, Clement K et al (1996) Clinical phenotypes, insulin secretion, and insulin sensitivity in kindreds with maternally inherited diabetes and deafness due to mitochondrial tRNALeu(UUR) gene mutation. Diabetes 45:478-487

14. Brandle M, Lehmann R, Maly FE, Schmid C, Spinas GA (2001) Diminished insulin secretory response to glucose but normal insulin and glucagon secretory responses to arginine in a family with maternally inherited diabetes and deafness caused by mitochondrial $t R N A(L E U(U U R))$ gene mutation. Diabetes Care 24:1253-1258 
15. Maassen JA, T Hart LM, Van Essen E et al (2004) Mitochondrial diabetes: molecular mechanisms and clinical presentation. Diabetes 53(Suppl 1):S103-S109

16. Lowell BB, Shulman GI (2005) Mitochondrial dysfunction and type 2 diabetes. Science 307:384-387

17. Rubi B, del Arco A, Bartley C, Satrustegui J, Maechler P (2004) The malate-aspartate NADH shuttle member Aralar1 determines glucose metabolic fate, mitochondrial activity, and insulin secretion in beta cells. J Biol Chem 279:55659-55666

18. de Andrade PB, Casimir M, Maechler P (2004) Mitochondrial activation and the pyruvate paradox in a human cell line. FEBS Lett 578:224-228

19. Merglen A, Theander S, Rubi B, Chaffard G, Wollheim CB, Maechler P (2004) Glucose sensitivity and metabolism-secretion coupling studied during two-year continuous culture in INS-1E insulinoma cells. Endocrinology 145:667-678

20. Maechler P, Wang H, Wollheim CB (1998) Continuous monitoring of ATP levels in living insulin secreting cells expressing cytosolic firefly luciferase. FEBS Lett 422:328-332

21. Rubi B, Ishihara H, Hegardt FG, Wollheim CB, Maechler $P$ (2001) GAD65-mediated glutamate decarboxylation reduces glucose-stimulated insulin secretion in pancreatic beta cells. J Biol Chem 276:36391-36396

22. Rubi B, Ljubicic S, Pournourmohammadi S et al (2005) Dopamine D2-like receptors are expressed in pancreatic beta cells and mediate inhibition of insulin secretion. J Biol Chem 280:36824-36832

23. Appleby RD, Porteous WK, Hughes G et al (1999) Quantitation and origin of the mitochondrial membrane potential in human cells lacking mitochondrial DNA. Eur J Biochem 262:108-116

24. Narushima M, Kobayashi N, Okitsu T et al (2005) A human betacell line for transplantation therapy to control type 1 diabetes. Nat Biotechnol 23:1274-1282

25. Silvestri G, Moraes CT, Shanske S, Oh SJ, DiMauro S (1992) A new mtDNA mutation in the $\operatorname{tRNA}(\mathrm{Lys})$ gene associated with myoclonic epilepsy and ragged-red fibers (MERRF). Am J Hum Genet 51:1213-1217

26. Brini M, Pinton P, King MP, Davidson M, Schon EA, Rizzuto R (1999) A calcium signaling defect in the pathogenesis of a mitochondrial DNA inherited oxidative phosphorylation deficiency. Nat Med 5:951-954

27. Turrens JF (2003) Mitochondrial formation of reactive oxygen species. J Physiol 552:335-344

28. Beretta S, Mattavelli L, Sala G et al (2004) Leber hereditary optic neuropathy mtDNA mutations disrupt glutamate transport in cybrid cell lines. Brain 127:2183-2192

29. Sandhu JK, Sodja C, McRae K et al (2005) Effects of nitric oxide donors on cybrids harbouring the mitochondrial myopathy, encephalopathy, lactic acidosis and stroke-like episodes (MELAS) A3243G mitochondrial DNA mutation. Biochem J 391:191-202
30. Vives-Bauza C, Gonzalo R, Manfredi G, Garcia-Arumi E, Andreu AL (2006) Enhanced ROS production and antioxidant defenses in cybrids harbouring mutations in mtDNA. Neurosci Lett 391:136-141

31. Herst PM, Tan AS, Scarlett DJ, Berridge MV (2004) Cell surface oxygen consumption by mitochondrial gene knockout cells. Biochim Biophys Acta 1656:79-87

32. Park SY, Chang I, Kim JY et al (2004) Resistance of mitochondrial DNA-depleted cells against cell death: role of mitochondrial superoxide dismutase. J Biol Chem 279:7512-7520

33. Vergani L, Floreani M, Russell A et al (2004) Antioxidant defences and homeostasis of reactive oxygen species in different human mitochondrial DNA-depleted cell lines. Eur J Biochem 271:3646-3656

34. Miranda S, Foncea R, Guerrero J, Leighton F (1999) Oxidative stress and upregulation of mitochondrial biogenesis genes in mitochondrial DNA-depleted HeLa cells. Biochem Biophys Res Commun 258:44-49

35. Floreani M, Napoli E, Martinuzzi A et al (2005) Antioxidant defences in cybrids harboring mtDNA mutations associated with Leber's hereditary optic neuropathy. Febs J 272:1124-1135

36. Trifunovic A, Hansson A, Wredenberg A et al (2005) Somatic mtDNA mutations cause aging phenotypes without affecting reactive oxygen species production. Proc Natl Acad Sci U S A 102:17993-17998

37. Ballinger SW, Shoffner JM, Hedaya EV et al (1992) Maternally transmitted diabetes and deafness associated with a $10.4 \mathrm{~kb}$ mitochondrial DNA deletion. Nat Genet 1:11-15

38. DeBlockCE,DeLeeuwIH,MaassenJA,BallauxD,MartinJJ(2004)A novel 7301-bp deletion in mitochondrial DNA in a patient with Kearns-Sayre syndrome, diabetes mellitus, and primary amenorrhoea. Exp Clin Endocrinol Diabetes 112:80-83

39. van den Ouweland JM, de Klerk JB, van de Corput MP et al (2000) Characterization of a novel mitochondrial DNA deletion in a patient with a variant of the Pearson marrow-pancreas syndrome. Eur J Hum Genet 8:195-203

40. Silva JP, Kohler M, Graff C et al (2000) Impaired insulin secretion and beta-cell loss in tissue-specific knockout mice with mitochondrial diabetes. Nat Genet 26:336-340

41. Soejima A, Inoue K, Takai D et al (1996) Mitochondrial DNA is required for regulation of glucose-stimulated insulin secretion in a mouse pancreatic beta cell line, MIN6. J Biol Chem 271:26194-26199

42. Kennedy ED, Maechler P, Wollheim CB (1998) Effects of depletion of mitochondrial DNA in metabolism secretion coupling in INS-1 cells. Diabetes 47:374-380

43. Tsuruzoe K, Araki E, Furukawa N et al (1998) Creation and characterization of a mitochondrial DNA-depleted pancreatic betacell line: impaired insulin secretion induced by glucose, leucine, and sulfonylureas. Diabetes 47:621-631 